\title{
Level of Parent Adolescent Communication on Sexual and Reproductive Health Issues and Associated Factors among Debre Markos Preparatory School Students, in Debre Markos Town, East Gojjam, Zone, Ethiopia
}

\author{
Mekuanint Taddele $^{1, *}$, Dube Jara ${ }^{1}$, Alebachew hunie ${ }^{2}$ \\ ${ }^{1}$ Department of Public health, College of Health science, Debre Markos University, Debre Markos, Ethiopia \\ ${ }^{2}$ School of Medicine, Debre Markos University, Debre Markos, Ethiopia
}

Copyright $\mathrm{C} 2018$ by authors, all rights reserved. Authors agree that this article remains permanently open access under the terms of the Creative Commons Attribution License 4.0 International License

\begin{abstract}
Background: World Health Organization defines adolescents as those in the age group of 10-19. While parent-adolescent sexual and reproductive health communication is one potential source of sexual and reproductive health information for adolescents. But, it appears to be inadequately practiced in Ethiopia. Objective: To assess level of parent adolescent communication on sexual and reproductive health issues and associated factors among Debre Markos preparatory school students in Debre Markos Town, East Gojjam Zone, Ethiopia. Methods: An institution-based cross-sectional study was conducted among preparatory school students from 22 sections in Debre Markos Town from December 15/2016-March to $15 / 2017$. Simple random sampling technique was used to select 394 participants from 1653 total students. Self-administered questionnaire was employed. Results: A total of 394 students were participated in our study from Debre Markos preparatory school. Of these, 232 (58.9\%) were males and $162(41.1 \%)$ were females. The study showed that communication between adolescence and parent was 114 (28.9\%), from this majority of students preferred to discuss with their mothers (42.1\%) than others. Knowledge about reproductive health issues $[\mathrm{AOR}=4.10695 \% \mathrm{CI}: 2.328$, 7.243)] and knowledge about contraceptive $[\mathrm{AOR}=2.119$ $95 \% \quad$ CI: (1.107, 4.054] had significant association .Conclusion: This study revealed that parent adolescent communication on sexual and reproductive health issues is inadequate. Therefore, there is a need to equip and educate parents and students on different sexual and reproductive health issues to prevent adolescences from risk sexual behaviors.
\end{abstract}

Keywords Parent, Adolescent, Sexually Transmitted Disease, Sexual, Reproductive Health Issue,

\section{Communication}

\section{Introduction}

Adolescence is transitional period from childhood to adulthood, characterized by significant physiological, psychological and social changes. WHO defines adolescence as those in the age group of 10-19 and youth 10-24 years. Young people constitute around 1.8 billion and represent $27 \%$ of the world's population. The world currently cares for a historic highest number of adolescents; about 1.2 billion adolescents need proper education, health and other life skills to ensure a better future for themselves and their countries. The adolescent population in Ethiopia has been increasing during the last few decades. Currently, adolescents constitute about $24 \%$ while young adults $10-24$ years constitute about $30 \%$ of the total population (1).

Sexual and reproductive growth and development is one of the remarkable changes during this period and it is when parents are expected to socialize their children, in which parent-adolescent sexual and reproductive health (SRH) communication is one (1).

Sexuality and reproductive health are among the most fundamental aspects of life. Sexual Health is about the enhancement of life and personal relations, and not merely counseling and care related to reproduction and STDs (2, $3)$.

Adolescents, having survived all childhood health problems, have been enjoying a relatively low morbidity and mortality period in the past. At present, as a result of civilization, urbanization and change in life style, the health of adolescents is increasingly at stake (3). The health threats for adolescents today are predominantly behavioural rather than biomedical and more of today's 
adolescents are involved in health behaviors with potential for serious consequences. Sexually transmitted diseases including HIV/AIDS and other reproductive health problems are the greatest threats to their well-being $(1,3)$.

In Ethiopia, like in other sub Saharan African countries, sexual and reproductive health problems of adolescents are high. About $12 \%$ of adolescent women are already mothers or pregnant with their first child and $60 \%$ of adolescent pregnancies are unwanted or unintended $(4,5)$. According to EDHS report, $1.9 \%$ and $3.8 \%$ of female and male adolescents had premarital sex respectively, among those who have premarital sex only $45.5 \%$ women and $60 \%$ men used condom. This unsafe sexual intercourse leads to HIV prevalence of $0.2 \%$ among adolescent women (4).

Parent-adolescent communication regarding sexual and reproductive health issues is more likely to reduce adolescent risk-taking sexual behaviors. Communication between parents and adolescents about sexual and reproductive health issues, however; is difficult for parents. A review of literature was done on the barriers that prevent communication between parents and adolescents regarding sexual and reproductive health issues. Sexual communication is crucial aspect of sexual socialization and fundamental process of parents convey ideas, values, beliefs, expectations, information and knowledge to their children (6).

Parent-adolescent communication is important because sexual activities begin at early age for many adolescents. Rates of sexual initiation during young adulthood are rising or remaining unchanged in many developing countries, and high HIV prevalence adds to the risks associated with early sexual activity. Parents have significant potential to reduce sexual risk behaviors and promote healthy adolescent sexual development. One way that parents can realize this potential is through communicating with their adolescents about sexual behaviors and decision-making. School based comprehensive sex education programs more often focus on the delay of sexual activity, training in sexual negotiation, communication skills, information about obtaining contraceptive and reproductive health services. Both abstinence and comprehensive programs aimed at this group tend to focus on puberty, pregnancy, HIV information, assertiveness and refusal skills. Parent-based approaches could be an effective strategy in the range of programs to delay sexual intercourse, reduce teenage pregnancy and sexual transmitted infections (2).

Parents need accurate information and support to feel more comfortable and confident that they possess the necessary communication skills to be effective in discussing risk-taking sexual behaviors with their adolescents as effective familial sex communication can lead to decreased adolescent risk-taking sexual behaviors, discomfort experienced by parents and their adolescents in speaking about adolescent sexuality can prevent effective sex education from occurring. One third of women worldwide give birth before the age of 20 each year and are at increased risk of morbidity and mortality due to obstetric complications (3).

Annually, 5,000,000 and 70,000 adolescents between the ages of 15 and 18 have unsafe abortions and abortion related deaths respectively (4).

Studies suggested that adolescents have limited knowledge about SRH and know little about the natural process of puberty. This limited knowledge about reproductive health may have serious consequences. Adolescents frequently engage in risky sexual behaviors that adverse health outcome including unintended pregnancy and sexually transmitted diseases. Parent-adolescent sexual and reproductive health communication is one which helps to transmit values, beliefs and expectations about SRH matters to their adolescents. Evidence has shown that the communication protects the young from engaging in risky sexual practices and associated adverse health consequences. Determining parent-adolescent communication about sexual and reproductive health issues helps to design appropriate intervention programs (8).

Adolescents often engage in various risk sexual behaviors that can result in adverse health, social and economic consequences. Discomfort experienced by parents and their adolescents in speaking about adolescent reproductive health can prevent effective reproductive health communication from occurring (12).

Adolescents have been identified as being at elevated risk for HIV infection, since the AIDS epidemic has had a disproportionate impact on minorities, black and Hispanic adolescents may be at an even higher risk than nonminority teenagers. Similarly, rates of sexually transmitted diseases and unintended pregnancy are especially high among minority adolescents (14).

\section{Methods and Materials}

\subsection{Study Area, Setting and Period}

The study was conducted in Debre Markos preparatory school from February 20-25/ 2017. Debre Markos Town is found in Amhara regional state which is $300 \mathrm{~km}$ far from Addis Ababa, Northwest Ethiopia and $265 \mathrm{~km}$ far from Bahir Dar. It has an altitude of 2450-2520 m above sea level and average temperature of 15-22 degree centigrade.

There were 84 teachers, from this 69 were males and 15 were females. Total number of students were 1563 and from this 743 were grade $11($ males $=385$, females $=358)$, the remaining 820 students were grade 12 (male $=434$, females $=416$ ). Total numbers of section were 22. And averagely it contained 60 students.

\subsection{Study Design and Population}

Institutional based cross-sectional study design was conducted among governmental preparatory students in the district. 


\subsection{Sample Size and Sampling Techniques}

The sample size was estimated based on single population proportion (p). The formula:

$$
\mathbf{n}=\frac{(Z \alpha / 2)^{2} P(1-P)}{(\mathbf{d})^{2}}
$$

Where $n$ is sample size, $P$ (proportion of adolescent's who have communication problem with parents on sexual and reproductive health issues) $\& \mathrm{~d}$ is margin of error. $\mathrm{P}=$ $37 \%$ (proportion of students communicating on SRH issues with parents which is taken from previously study done in Debre Markos (3). Allowing 5\% for expected margin of error $(d)$ and $95 \%$ confidence level $\left(Z_{\alpha / 2}=1.96\right)$, the required sample size $n$ will be

Significance level $5 \%(\alpha=0.05)$, and $Z \alpha / 2=1.96$

Margin of error $5 \%(\mathrm{D}=0.05)$.

$(\mathrm{N}=1563)$ is:

$$
\begin{gathered}
\mathbf{n}=\frac{(Z \alpha / 2)^{2} P(1-P)}{(\mathbf{d})^{2}} \\
=1.96^{2} \times 0.37 \times 0.63 / 0.05^{2}, \mathrm{n}=358
\end{gathered}
$$

Assuming $10 \%$ non-response rate; $\mathrm{n}=358+10 \%=394$. So, the final sample size was 394 .

\subsection{Sampling Procedure}

A total number, 394 sample sizes divided by the total number of sections i.e. 22 (from 10 sections of grade 11 and 12 sections of grade 12) and approximately it would be 18 and this proportion would prefer because of the average students in each section was similar. So, based on the proportion, simple random sampling (lottery method) was applied to select 18 students from each section by their number from the roster.

\subsection{Data Collection Methods}

Interviewer administered structured and pre-tested questionnaire was used for collecting primary data from the study population.

The questionnaire includes socio-demographic characteristics, like age, sex, educational status of parents, ethnicity, religion, occupation of parents, family size, place of residence, economic variables, knowledge of students on sexual and reproductive health issues, living arrangements of the students, parental preference/ gender preference and practice of discussion/frequency. It had closed type of questions that were commonly used in cross-sectional studies. The questionnaire was prepared in English, translated to Amharic and back translated to English for consistency. Two days intensive training was given for data collectors and supervisors. As a part of practical exercise, data collection tool was pre-tested prior to the study other than the study site at Lumame preparatory school. All the necessary modifications were made. The method used to select students from each sections were, the total number of sample size (394) divided by the total number of sections i.e. 22(from 10 sections of grade 11 and 12 sections of grade 12) and approximately it would be 18 . So 18 students from each section were selected. Then the data collected from the study participants were checked for completeness by one supervisor with the principal investigator in collaboration with data collectors throughout the process of data collection daily.

\subsection{Data Processing and Analysis}

The collected data were edited, coded and entered using Epi-Data version 3.1 and exported to SPSS version 20.0 for analysis. Descriptive statistics was done to compute frequency, percentage and mean for independent and dependent variables. Binary logistic regression analysis was done to ascertain the association between explanatory variables and outcome. Variables with significant association in the bivariate analysis were entered in to multivariate analysis to determine independent predictors of adolescent-parent communication on sexual and reproductive health issues. Selection of variables for inclusion in the final multivariate regression model was based on the result of P-value significance during binary logistic regression statistical test (p-value $<0.25$ ). Re-categorization (merging) of some categories to avoid small values in the cell was done. Odds ratio (OR) with $95 \%$ confidence interval (CI) was used as an effect measure.

\subsection{Ethical Approval}

Formal letter were obtained from Debre Markos University, school of medicine. Permission was obtained from school administration. Informed verbal consent was obtained from every participant after explaining the purpose of the study in detail. Questionnaires were coded instead of using names as identification and hence, confidentiality was assured throughout the study. Those who were not willing to participate or refuse on the middle of the study had full right.

\section{Results}

\subsection{Socio-demographic Characteristics}

Among 394 students data were collected from all; this made the response rate $100 \%$. In this study 394 students were participated and from these, 232(58.9\%) were males, $162(41.1 \%)$ were females. And $166(42.1 \%)$ were grade 11 whereas, 228(57.9\%) were grade 12. Majority 381(96.7\%) and $387(98.2 \%)$ were orthodox and Amhara respectively. More than half 201(51\%) of the students living with both mother and father, few of $22(5.6 \%)$ living with their father only, others $79(20.1 \%)$ living with their mother only, $16(4.1 \%)$ living with their friend's, $28(7.1 \%)$ live lonely and $48(12 \%)$ live with relatives (Table 1 ). 
Table 1. Socio demographic characteristics of students at Debremarkos preparatory school, in Debremarkos Town, East Gojjam, Ethiopia from February 20-25/2017.

\begin{tabular}{|c|c|c|}
\hline Variable & Frequency & Percent \\
\hline $\begin{array}{c}\text { Sex } \\
\text { Female } \\
\text { Male }\end{array}$ & $\begin{array}{l}162 \\
232\end{array}$ & $\begin{array}{l}41.1 \% \\
58.9 \%\end{array}$ \\
\hline $\begin{array}{c}\text { Grade level } \\
\text { Grade } 11 \\
\text { Grade } 12\end{array}$ & $\begin{array}{l}166 \\
228\end{array}$ & $\begin{array}{l}42.1 \% \\
57.9 \%\end{array}$ \\
\hline $\begin{array}{c}\text { Religion } \\
\text { Orthodox } \\
\text { Muslim } \\
\text { Other }\end{array}$ & $\begin{array}{c}381 \\
2 \\
11\end{array}$ & $\begin{array}{c}96.7 \% \\
.5 \% \\
2.8 \%\end{array}$ \\
\hline $\begin{array}{c}\text { Ethnicity } \\
\text { Amhara } \\
\text { Oromo } \\
\text { Tigray }\end{array}$ & $\begin{array}{c}387 \\
5 \\
2\end{array}$ & $\begin{array}{c}98.2 \% \\
1.3 \% \\
0.5 \%\end{array}$ \\
\hline $\begin{array}{l}\text { Living condition } \\
\text { With both mother and father } \\
\text { Only with father } \\
\text { Only with mother } \\
\text { Others }\end{array}$ & $\begin{array}{c}201 \\
22 \\
79 \\
92\end{array}$ & $\begin{array}{c}51 \% \\
5.6 \% \\
20.1 \% \\
23.4 \%\end{array}$ \\
\hline $\begin{array}{c}\text { Father's education status } \\
\text { Unable to read and write } \\
\text { Read and write only } \\
\text { Grade } 1-8 \\
\text { Grade } 9-12 \\
\text { Above grade } 12\end{array}$ & $\begin{array}{c}33 \\
112 \\
59 \\
56 \\
134\end{array}$ & $\begin{array}{c}8.4 \% \\
28.4 \% \\
15.4 \% \\
14 \% \\
34 \%\end{array}$ \\
\hline $\begin{array}{l}\text { Mother's education status } \\
\text { Unable to read and write } \\
\text { Read and write only } \\
\text { Grade } 1-8 \\
\text { Grade } 9-12 \\
\text { Above grade } 12\end{array}$ & $\begin{array}{c}100 \\
87 \\
48 \\
56 \\
103\end{array}$ & $\begin{array}{l}25.4 \% \\
22.1 \% \\
12.1 \% \\
14.2 \% \\
26.1 \%\end{array}$ \\
\hline $\begin{array}{c}\text { Mother's occupation status } \\
\text { House wife } \\
\text { Government employed } \\
\text { Private worker } \\
\text { Merchant } \\
\text { Farmer } \\
\end{array}$ & $\begin{array}{c}191 \\
79 \\
14 \\
50 \\
60\end{array}$ & $\begin{array}{c}48.5 \% \\
20.1 \% \\
3.6 \% \\
12.7 \% \\
15.2 \% \\
\end{array}$ \\
\hline
\end{tabular}

As stated on Table 2 below, 295(74.9\%) students never communicate about contraceptives with their mother's but $22(5.6 \%)$ of students communicate about contraceptives always. On the other hand, 327(83\%) students never communicate about contraceptives with their father's but 16(4.1\%) communicate about contraceptives always with their father's.169(42.9\%) of students never communicate about HIV/AIDS with their mothers but 182(46.2\%) students communicate about HIV/AIDS sometimes with their mothers in addition 208(52.8\%) of students never communicate about HIV/AIDS with their fathers but 143(36.3\%) students communicate sometimes about HIV/AIDS with their fathers.

Table 2. Adolescent's sexual and reproductive health communications with mother and father. in Debre Markos Town, East Gojjam Zone Ethiopia, from February 20- 25/2017.

\begin{tabular}{|c|c|c|c|c|}
\hline \multirow{2}{*}{$\begin{array}{l}\text { Parent-adolescent } \\
\text { SRH communications. }\end{array}$} & \multirow{2}{*}{ Parent type } & \multicolumn{3}{|c|}{ Frequency of communications } \\
\hline & & Never $n(\%)$ & Sometimes n (\%) & Always n (\%) \\
\hline \multirow{2}{*}{ Communication about contraceptives. } & Mother & $295(74.9 \%)$ & $77(19.5 \%)$ & $22(5.6 \%)$ \\
\hline & Father & $327(83 \%)$ & $51(12.9 \%)$ & $16(4.1 \%)$ \\
\hline \multirow{2}{*}{ Communication about importance of condoms. } & Mother & $359(91.1 \%)$ & $25(6.3 \%)$ & $10(2.5 \%)$ \\
\hline & Father & $365(77.4 \%)$ & $102(15.3 \%)$ & $8(2 \%)$ \\
\hline \multirow{2}{*}{ Communication about HIV/AIDS. } & Mother & $169(42.9 \%)$ & $182(46.2 \%)$ & $43(10.9 \%)$ \\
\hline & Father & $208(52.8 \%)$ & $143(36.3 \%)$ & $43(10.9)$ \\
\hline \multirow{2}{*}{ Communication about pregnancy } & Mother & $305(77.4 \%)$ & $73(18.5 \%)$ & $16(4.1 \%)$ \\
\hline & Father & $359(91.1 \%)$ & $24(6.1 \%)$ & $11(2.8 \%)$ \\
\hline \multirow{2}{*}{ Communication about STDs } & Mother & $261(66.2 \%)$ & $118(29.9 \%)$ & $15(3.8 \%)$ \\
\hline & Father & $286(72.6 \%)$ & $91(23.1 \%)$ & $17(4.3 \%)$ \\
\hline \multirow{2}{*}{ Communication about how to handle } & Mother & $249(63.2 \%)$ & $99(25.1 \%)$ & $46(11.7 \%)$ \\
\hline & Father & $288(73.1 \%)$ & $72(18.3 \%)$ & $34(8.6 \%)$ \\
\hline \multirow{2}{*}{ Communication about when to start having sex } & Mother & $349(88.6 \%)$ & $32(8.1 \%)$ & $13(3.3 \%)$ \\
\hline & Father & $349(88.6 \%)$ & $36(9.1 \%)$ & $9(2.3 \%)$ \\
\hline
\end{tabular}


As depicted in Table 3 below, major reasons for students not communicating on SRH issues with their parents were, the first was cultural taboos $198(50.3 \%)$ of the students, because their parents are busy accounts 57(14.5\%) of students and $25(6.3 \%)$ of the students did not communicate with their parents due to expectation of their parents' knowledge about SRH issue not enough.

Table 3. Major reasons of respondents for not communicating on SRH issues with their parents, in Debremarkos preparatory schools, in DebreMarkos town, East Gojjam, Zone Ethiopia, from February 2025/2017.

\begin{tabular}{|c|c|c|}
\hline Variables & frequency & percent \\
\hline Cultural taboos & 198 & $50.3 \%$ \\
Because of my parents are busy & 57 & $14.5 \%$ \\
Expectations of parent's knowledge about & 25 & $6.3 \%$ \\
SRH issue not enough. & & \\
\hline
\end{tabular}

\subsection{Risk Factors Associated with Communication of Adolescents with Their Parents in Debre Markos Preparatory School, Debre Markos Town, East Gojjam Zone, Ethiopia}

From 162 female students, 48(29.6\%) discussed about $\mathrm{RH}$ issues with their parents. But $114(70.4 \%)$ do not had discussion with parents. From 232 male students 66 $(28.5 \%)$ had discussion on SRH issue with their parents, but $166(71.5 \%)$ did not discuss. From 166 grade 11 students $39(23.5 \%)$ discussed about SRH issue with parents whereas, 127(76.5\%) did not discuss on SRH issue and from grade 12 students $75(32.9 \%$ ) discussed on SRH issue but $153(67.1 \%$ ) did not discuss on SRH issue. From 250 students that have knowledge about SRH issue
96(38.4\%) discussed with their parents and from 144 who did not have knowledge about SRH issue 18(12.5\%) students discussed about SRH issue. As can be seen from table -4 below, from those predictor variables seen to have significant association with discussion of parent adolescent on sexual and reproductive health issues under bivariate analysis, knowledge about $\mathrm{RH}$ issue $[\mathrm{AOR}=4.10695 \% \mathrm{CI}$ : 2.328-7.243)] and knowledge about contraceptive [AOR=2.119 95\% CI:(1.107, 4.054] had statically significant association relative to who do not had knowledge on RH issues. But grade level [AOR $=0.778$ 95\%CI: 0.481, 1.259)], having sexual intercourse [AOR $=0.488$ 95\%CI: $0.132,1.807$ ) and interest about importance of discussing about RH with parent [AOR $=2.86895 \%$ CI: $0.946,8.693)]$ had significant association on bivariate analysis but had no significant association on multivariate analysis on parent adolescent discussion.

The finding also revealed that students who had knowledge about RH and contraceptive were more likely to discuss about RH issue with their parents as compared to their counterparts. It was understood from the bivariate analysis three factors could be considered as predictor variables in individually determining the outcomes of the study. Following this, a multivariate analysis was applied using multiple logistic regression models to control confounding effects for the three significantly associated variables and also for the other two variables that entered in to the model based on variable selection criteria, which were selected through bivariate analysis, and clearly understand their independent predicting ability (Table 4).

Table 4. Multiple logistic regressions for risk factors of parent adolescence communication about RH issue in Debremarkos preparatory school, Debre Markos town East Gojjam Zone, February 20-25/2017.

\begin{tabular}{|c|c|c|c|c|c|c|}
\hline \multirow{2}{*}{ Variables } & \multirow{2}{*}{ Categories } & \multicolumn{2}{|c|}{$\begin{array}{l}\text { Communication with } \\
\text { parents }\end{array}$} & \multirow{2}{*}{$\begin{array}{l}\text { Crude odds ratio } \\
\qquad(95 \% \mathrm{CI})\end{array}$} & \multirow[t]{2}{*}{$\begin{array}{l}\text { Adjust odds ratio } \\
(\mathrm{AOR})(95 \% \mathrm{CI})\end{array}$} & \multirow{2}{*}{$\mathrm{p}$ - value } \\
\hline & & $\begin{array}{c}\text { Yes } \\
\mathrm{N}(\%)\end{array}$ & $\begin{array}{c}\text { No } \\
\mathrm{N}(\%)\end{array}$ & & & \\
\hline Grade level & $\begin{array}{l}\text { Grade } 11 \\
\text { †Grade } 12\end{array}$ & $\begin{array}{l}39 \\
75\end{array}$ & $\begin{array}{l}127 \\
153 \\
\end{array}$ & $\begin{array}{c}0.626(0.398,0.985) \\
1.00\end{array}$ & $\begin{array}{c}0.778(0.481,1.259) \\
1.00\end{array}$ & 0.308 \\
\hline Knowledge about RH & $\begin{array}{r}\text { Yes } \\
\dagger \text { no }\end{array}$ & $\begin{array}{l}96 \\
18 \\
\end{array}$ & $\begin{array}{l}154 \\
126\end{array}$ & $\begin{array}{c}4.364(2.503,7.607) \\
1.00\end{array}$ & $\begin{array}{c}4.106(2.328,7.243) \\
1.00\end{array}$ & $<0.001 *$ \\
\hline Having sexual intercourse & $\begin{array}{l}\text { Yes } \\
\dagger \text { no }\end{array}$ & $\begin{array}{c}3 \\
119 \\
\end{array}$ & $\begin{array}{c}19 \\
261 \\
\end{array}$ & $\begin{array}{c}0.371(0.108,1.28) \\
1.00\end{array}$ & $\begin{array}{c}0.488(0.132,1.807) \\
1.00\end{array}$ & 0.283 \\
\hline Knowledge about contraceptive & $\begin{array}{l}\text { Yes } \\
\dagger \text { No }\end{array}$ & $\begin{array}{c}100 \\
14 \\
\end{array}$ & $\begin{array}{c}214 \\
66 \\
\end{array}$ & $\begin{array}{c}2.203(1.181,4.110) \\
1.00\end{array}$ & $\begin{array}{c}2.119(1.107,4.054) \\
1.00\end{array}$ & $0.023 *$ \\
\hline $\begin{array}{c}\text { Interest about importance of } \\
\text { discussing about RH with parent }\end{array}$ & $\begin{array}{l}\text { Yes } \\
\dagger \text { No }\end{array}$ & $\begin{array}{c}110 \\
4\end{array}$ & $\begin{array}{c}254 \\
26\end{array}$ & $\begin{array}{c}2.815(0.960,8.258) \\
1.00\end{array}$ & $\begin{array}{c}2.868(0.946,8.693) \\
1.00\end{array}$ & 0.063 \\
\hline
\end{tabular}

†reference category, ${ }^{*}$ statistically significant $(\mathrm{p}$ value $<0.05), \mathrm{CI}=$ confidence interval 


\section{Discussion}

The study revealed that communication between adolescents and their parents was $28.9 \%$. The result revealed that the communication between parents and adolescents frequency were in line with the study done in Benishangul Gumuz regional state $28.9 \%$, Hawse (30.4\%), previous study done in Debre Markos (36.9\%). However, this finding is very low comparing with the study conducted in Mekele Town (57.6\%), Zimbabwe (44\%) and Malawi (74\%) schools(6). Majority of adolescents discussed on SRH issues like, avoiding premarital sexual intercourse. In line with this, the study done in Debre Markos before and in Harer, also showed that most of the students discussed on avoiding premarital sex, this is may be due to fear of risk of HIV/AIDS, and unwanted pregnancy.

In this study, students preferred their mother's for discussion and the reason may be majority of mother's were house wife and they had enough time to be with their children. On the other hand, around $1 / 3^{\text {rd }}$ of participant's fathers were farmers and they may not have knowledge about SRH, similarly studies done in east Ethiopia, Harar showed that mothers are the first preference for SRH issue discussion (1) and on the other study done in Debre Markos showed that mothers are the second choice next to peers to discuss about SRH issue (3).

On the contrary, more than $2 / 3^{\text {rd }}$ of the students were not communicating even if the participants had interest to communicate on SRH issues with their parents. This may be since majority of their parents were busy and had little time to be with their children, cultural taboos, demographic and cultural difference, and difference in accessing SRH information.

The study also showed that, greater than $2 / 3^{\text {rd }}$ never communicated about importance of condom, unintended pregnancy, STDs including HIV/AIDs, contraceptives and how to handle sexual pressure from their peers with their parents. The reason may be lack of knowledge of parent's about SRH issues, being busy and cultural taboos.

The finding from this study showed that having knowledge about SRH issues and students who ever had knowledge about contraceptives were more likely to communicate on SRH issues with their parents than those who have not. This is due to students who have knowledge about SRH issue was eager to communicate with parents on SRH issues. In line with this a study done in Debre Markos also showed that, those students who had ever got SRH information were 2 times more likely to communicate SRH issues with their parents than those who had never got SRH information (3). This may be due to respondents who have some awareness might be more eager to communicate SRH issues and the information they got may pave the way for initiation of communication.

This study also showed that there is a significant difference between grade 11 and grade 12 for discussing about SRH issues with parents even if the association is not significant on multivariate analysis. As showed in the study, being grade 11 had negative association with discussing about SRH issue with parents. Similarly, the study done in Dire Dawa also revealed that, Grade 12 students were 1.6 times more likely to discuss on sexual and reproductive health issues with their parents than those in grade nine (9). The reason may be when the grade level and age increase, the chance of getting information on SRH issue increased. On the other hand, a study done in Debre Markos showed that Grade 12 students were less likely to communicate on SRH issues compared to grade 11 students (3).

\section{Conclusions}

This study revealed that parent adolescent communication on sexual and reproductive health issues is inadequate. Therefore; there is a need to equip and educate parents and students on different sexual and reproductive health issues to prevent adolescences from risk sexual behaviors.

\section{Conflict of Interests}

The authors declare that they have no competing interests.

\section{Authors' Contribution}

Alebachew Hunie Mekuanint Taddele, Dubie Jara were participated in proposal writing, analyzing the data, and drafting the paper. Mekuanint Taddele prepared the manuscript for publication. All authors revised subsequent drafts of the paper.

\section{Acknowledgements}

The author's deep gratitude goes to Debre Markos University, College of Medicine and Health Sciences for proper review and approval of this paper. The authors would also like to extend their gratitude to Debremarkos preparatory school for giving permission to conduct the study, data collectors, and supervisors for valuable contribution for the success of this study.

\section{REFERENCES}

[1] Dessie Y, Berhane Y, Worku A. Parent-Adolescent Sexual and Reproductive Health Communication Is Very Limited and Associated with Adolescent Poor Behavioral Beliefs and Subjective Norms: Evidence from a Community Based Cross-Sectional Study in Eastern Ethiopia, PLOS ONE | DOI:10.1371/journal.pone.0129941 July 13, 2015 
[2] Berhane F,Berhane Y, Fantahun M. Adolescents' health service utilization pattern and preferences: Consultation for reproductive health problems and mental stress are less likely. Ethiop. J. Health Dev. 2005;19(1)

[3] Shiferaw K ,Getahun F , Asres G. Assessment of adolescents' communication on sexual and reproductive health matters with parents and associated factors among secondary and preparatory schools' students in Debremarkos town, North West Ethiopia, Shiferaw et al. Reproductive Health 2014, 11:2

[4] Ethiopian Demographic and Health Survey. Final Report Addis Ababa, Ethiopia and Calverton, Maryland, USA; 2012. Available

from:http://www.unicef.org/ethiopia/ET 2011 EDHS.pdf. Parent-Adolescent Sexual and Reproductive Health Communication PLOS

[5] World Health Organization (WHO, 2011) Unsafe abortion global and regional estimates of the incidence of unsafe abortion and associated mortality in 2008. ISBN: 978924 150111

8.: http://www.who.int/reproductivehealth/publications/uns afe_abortion/9789241596121/en/.

[6] Gebre Yesus D, Fantahun M (2010) Assessing communication on sexual and reproductive health issues among high school students with their parents, Bullen Woreda, Benishangul Gumuz Region, and North West Ethiopia. Ethiop J Health Dev 24: 89-95.

[7] Laursen B, W. A. Collins, Parent-Child Communication during Adolescence, CHAPTER 16.

[8] Fanta M, Lemma S, Sagaro GG, Meskele M, Factors associated with adolescent-parent communication of reproductive health issues among high school and preparatory students in Boditi town, Southern Ethiopia 2016.

[9] Ayalew M, Mengistie B, Semahegn A. Adolescent - parent communication on sexual and reproductive health issues among high school students in Dire Dawa, Eastern Ethiopia: a cross sectional study. Ayalew et al. Reproductive Health 2014, 11:77

[10] Namisi, Wilson EK, Koo HP (2010) Mothers, fathers, sons, and daughters: gender differences in factors associated with parent-child communication about sexual topics. Reproductive Health 7: 31 doi: 10.1186/ 1742-4755-7-31 PMID: 21156057

[11] Wamoyi J, Fenwick A, Urassa M, Zaba B, Stones W: Parent child communication about sexual and reproductive health in rural Tanzania Implications for young people's sexual health interventions. Reprod Health 2010, 7(6):1-18

[12] Catherine S. Nundwe, case study on barriers to communication between parents and Adolescents concerning sexual and reproductive health issues2012.

[13] Adu-Mireku S (2003) Family communication about HIV/AIDS and sexual behaviour among senior secondary school students in Accra, Ghana. Afr Health Sci 3: 7-14. PMID: 12789082

[14] Paul-Ebhohimhen VA, Poobalan A, Teijlingen ER (2008) A systematic review of school-based sexual health interventions to prevent STI/HIV in sub-Saharan Africa. BMC Public Health 8: doi: 10.1186/1471-2458-1188-1184.

[15] Poulsen MN, Miller KS, Lin C, Fasula A, Vandenhoudt H, Wyckoff SC et al. (2010) Factors associated with parent-child communication about HIV/AIDS in the United States and Kenya: a cross-cultural comparison. AIDS Behav 14: 1083-1094. doi: 10.1007/s10461-009-9612-4 PMID: 19763811

[16] Dilorio C, Kellen M, Hockenberry E. Communication about sexual issues: Mothers, Fathers, and friends. Adolesc Health March 1999; 24(30):181-9.

[17] Miller BKS, Kotchick BA, Dorsey S, Forehand R, Ham AY (1998) Family Communication About Sex:What Are Parents Saying and Are Their Adolescents Listening?. Family Planning Perspectives 30:218-235. PMID: 9782044 